\title{
A library of thermoresponsive PEG-based methacrylate homopolymers: How do the molar mass and number of ethylene glycol groups affect the cloud point?
}

\author{
Qian Li, Anna P. Constantinou and Theoni K. Georgiou* \\ Department of Materials, Imperial College London, Royal School of Mines, Exhibition Road, SW7 2AZ, \\ London, UK
}

Correspondence to: Theoni K. Georgiou (E-mail: t.georgiou@imperial.ac.uk)

((Additional Supporting Information may be found in the online version of this article.))

\begin{abstract}
In this study, a novel library of thermoresponsive homopolymers based on poly (ethylene glycol) (EG) (m)ethyl ether methacrylate monomers is presented. $27 \mathrm{EG}$ based homopolymers were synthesized and three parameters, the molar mass (MM), the number of the ethylene glycol groups in the monomer, and the chemistry of the functional side group were varied to investigate how these affect their thermoresponsive behaviour. The targeted MMs of these polymers are varied from $2560 \mathrm{~g} \mathrm{~mol}^{-}$ $1,5000 \mathrm{~g} \mathrm{~mol}^{-1}, 8200 \mathrm{~g} \mathrm{~mol}^{-1}$ to $12000 \mathrm{~g} \mathrm{~mol}^{-1}$. Seven PEG-based monomers were investigated: ethylene glycol methyl ether methacrylate (MEGMA), ethylene glycol ethyl ether methacrylate (EEGMA), di(ethylene glycol) methyl ether methacrylate (DEGMA), tri(ethylene glycol) methyl ether methacrylate (TEGMA), tri(ethylene glycol) ethyl ether methacrylate (TEGEMA), penta(ethylene glycol) methyl ether methacrylate (PEGMA), nona(ethylene glycol) methyl ether methacrylate (NEGMA). Homopolymers of 2-(dimethylamino) ethyl methacrylate (DMAEMA) were also synthesized for comparison. The cloud points of these homopolymers were tested in different solvents and it was observed that it decreases as the number of EG group was decreased or the MM increased. Interestingly, the end functional group (methoxy or ethoxy) of the side group has an effect as well and is even more dominant than the number of EG groups.

KEYWORDS: thermoresponsive polymers, poly(ethylene glycol), ethylene glycol methacrylate; group transfer polymerization, lower critical solution temperature, LCST, homopolymer, temperatureresponsive, MEGMA, EEGMA, DEGMA, PEGMA TEGMA, TEGEMA, NEGMA, OEGMA
\end{abstract}

\section{INTRODUCTION}

In recent years, smart materials have gain significant scientific interest. Smart materials are materials able to respond to external stimulus, such as $\mathrm{pH}$, light, temperature and pressure. Thermoresponsive gels (TRGs) are one kind of smart materials which undergo a sol-gel transition when the temperature changes. ${ }^{1-5}$ This thermoresponsive property and their formation of a reversible gels makes TRGs promising materials for many biomedical applications, such as tissue engineering, ${ }^{6-8}$ protein purification, ${ }^{9} 3$ D bioprinting, ${ }^{10,}{ }^{11}$ drug delivery, ${ }^{8,}{ }^{12}$ gene therapy, ${ }^{13}$ and other industrial applications, for example, sensors, ${ }^{14,15}$ and catalysts. ${ }^{16}$ 
Thermoresponsive polymers are divided into two groups, the lower critical solution temperature (LCST) polymers and the upper critical solution temperature (UCST) polymers, based on how their solubility changes as the temperature changes. ${ }^{1,4}$ The LCST polymers form homogeneous solutions at low temperatures and at high temperature phase separation occurs (the solution appears cloudy and the polymer might precipitate out of solution). On the other hand, the UCST polymers are not soluble at lower temperature and they are in a transparent homogenous solution at higher temperatures. Our interest lies in LCST polymers because we aim at finding suitable polymers to be used as injectable gels or/and drug delivery. ${ }^{1,} 8$ These applications involve mixing the drug or cells with the polymer solution at room temperature in vitro; then upon injection, the polymer forms hydrogel in vivo due to the higher temperature of human body. LCST polymers with slightly lower than $37^{\circ} \mathrm{C}$ are ideal for these applications, as these ensure that in vivo gelation will take place. ${ }^{6,8}$

Poly (N-isopropyl acrylamide) (PNIPAAm) is one of most commonly studied LCST polymers with LCST at around $32^{\circ} \mathrm{C} .{ }^{3}, 4,17,18$ Many PNIPAAm based polymers form gels around body temperature and thus have been researched extensively for biomedical applications such as controlled cell transplantation, drug delivery system. ${ }^{19,20}$ However, some properties such as the cytotoxicity of the unreacted NIPAAm monomer and NIPAAm oligomers and the possible absorption of proteins have been found to limit the application of PNIPAAm polymers. ${ }^{21-}$ 23

Poly(ethylene glycol) (m)ethyl ether methacrylate based monomers can offer a great alternative to PNiPAAm based polymers because polyethylene glycol (PEG) is a nontoxic, FDA approved polymer that is resistance to the absorption of proteins. $5,24,25$ Thus, PEG based (meth)acrylate polymers have gained considerable interest the last 20 years. ${ }^{15,24-39}$ It is known that the number of EG groups will affect the LCST. $5,24,26,36$ However, in order to find the PEG based methacrylate alternative to PNIPAAm, a systematic study is needed. This is because it is well-documented that the LCST is affected by the molar mass (MM), thus only welldefined polymers of similar MM and narrow MM distribution should be compared. ${ }^{18,}$, $40-45$ Furthermore, the presence of even small end group of the polymer can affect their thermoresponsive behavior especially if this group is charged, thus all polymers compared should be prepared with the same polymerization method and if possible have a small, non-ionic group. ${ }^{18,46-49}$

Thus, in this study a library of 27 PEG based methacrylate polymer was synthesized and characterized to investigate the effect of not only of the number of EGs but also the end group on the EG side group while keeping the end functional groups of the polymers the same. To the best of our knowledge, this is the first time that such an extensive library of PEG based homopolymers has been studied. Specifically, seven monomers from PEG based methacrylate family were investigated as shown in Fig.1: ethylene glycol methyl ether methacrylate (MEGMA), ethylene glycol ethyl ether methacrylate (EEGMA), di(ethylene glycol) methyl ether methacrylate (DEGMA), tri(ethylene glycol) methyl ether methacrylate (TEGMA), tri(ethylene glycol) ethyl ether methacrylate (TEGEMA), penta(ethylene glycol) methyl ether methacrylate (PEGMA), and nona(ethylene glycol) methyl ether methacrylate (NEGMA). Homopolymers based on 2-(dimethylamino)ethyl methacrylate (DMAEMA) were also fabricated for comparison. The MMs of the homopolymers was carefully controlled from $2560 \mathrm{~g} \mathrm{~mol}^{-1}, 5000 \mathrm{~g} \mathrm{~mol}^{-1}, 8200$ $\mathrm{g} \mathrm{mol}^{-1}$ to $12000 \mathrm{~g} \mathrm{~mol}^{-1}$. After polymerization, the MMs were confirmed by GPC. The cloud points and hydrodynamic diameters of these homopolymers were investigated to reveal how the thermoresponsive properties were influenced. Group transfer polymerization (GTP) 50, 51 was chosen to fabricate the polymers because is a living polymerization method, ideal 
for the fabrication of methacrylate in large scales and because the functional group that remains at the end of the polymer backbone is one methyl methacrylate group, a non-ionic group.

\section{EXPERIMENTAL}

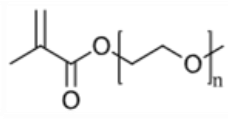

When:

n=1 (ethylene glycol) methyl ether methacrylate (MEGMA) $n=2$ di(ethylene glycol) methyl ether methacrylate (DEGMA) $\mathrm{n}=3$ tri(ethylene glycol) methyl ether methacrylate (TEGMA) $n=5$ penta(ethylene glycol) methyl ether methacrylate (PEGMA) $n=9$ nona(ethylene glycol) methyl ether methacrylate (NEGMA)

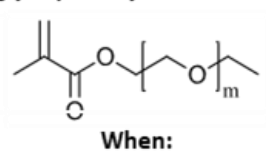

$\mathrm{m}=1$ (ethylene glycol) ethyl ether methacrylate (EEGMA) $m=3$ tri(ethylene glycol) ethyl ether methacrylate (TEGEMA)

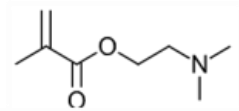

2-(dimethylamino) ethyl methacrylate (DMAEMA)

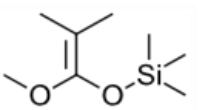

methyl trimethylsilyl dimethyl ketene acetal (MTS)
FIGURE 1 Chemical structures and abbreviations of all the monomers investigated.

\section{Materials}

The monomers: DMAEMA (MM=157.22 $\mathrm{g} \mathrm{mol}^{-1}$, 98\%), MEGMA (MM=144.17 $\left.\mathrm{g} \mathrm{mol}^{-1}, 99 \%\right)$, DEGMA (MM = $\left.188.22 \mathrm{~g} \mathrm{~mol}^{-1}, 95 \%\right)$, TEGMA $\left(\mathrm{MM}=232.27 \mathrm{~g} \mathrm{~mol}^{-1}, 93 \%\right)$, PEGMA (MM $=300 \mathrm{~g}$ $\left.\mathrm{mol}^{-1}\right)$, NEGMA (MM $=500 \mathrm{~g} \mathrm{~mol}^{-1}$ ) were purchased from Aldrich, UK. EEGMA (MM=158.20 $\left.\mathrm{g} \mathrm{mol}^{-1}, 98 \%\right)$ and TEGEMA (MM= $\left.246.30 \mathrm{~g} \mathrm{~mol}^{-1}, 95 \%\right)$ were purchased from Tokyo chemical industry, UK. The initiator, methyl trimethylsilyl dimethyl ketene acetal (MTS, 95\%), and the polymerization solvent, tetrahydrofuran (THF, HPLC grade, $\geq 99.9 \%$ ) and the free radical inhibitor 2,2-diphenyl-1-picrylhydrazyl hydrate (DPPH), were purchased from Aldrich, UK. Other chemicals: calcium hydride $\left(\mathrm{CaH}_{2}, \geq 90 \%\right)$, aluminum oxide activated basic $\left(\mathrm{Al}_{2} \mathrm{O}_{3} \cdot \mathrm{KOH}\right)$, deuterated chloroform (chloroform-d, 99.8 atom $\% \mathrm{D}$ ) were purchased from Aldrich, UK. The solvent in chromatography, (THF, GPC grad) and the visual test solvents, phosphate buffered saline (PBS, solution) were purchased from
Fischer Scientific. The precipitation solvent $n-$ hexane and ethanol were purchased from VWR chemicals.

Group Transfer Polymerization (GTP). All polymers reported in this study were fabricated using GTP. MTS was used as the initiator while tetrabutylammonium bibenzoate (TBABB) was used as a catalyst. TBABB was in house synthesized, following by Dicker et al. ${ }^{52}$

All the monomers were purified by passing twice through the column with basic aluminum oxide to remove any protic impurities and kept under argon under their distillation prior to polymerization. However, because of their high MMs PEGMA and NEGMA were not be distilled. Thus, the purification and polymerization steps were slightly different, according to Vamvakaki et al. ${ }^{38,53-55}$ Before purification, a $50 \%$ vol THF solution of the monomer was prepared. The mixture was then passed through the basic aluminum oxide column twice without adding DPPH to it. After purification, the monomer solution was stirred with calcium hydroxide as other monomers. During polymerization, the monomer solution was filtered before the addition to remove the calcium hydride.

All polymers were synthesized in similar way. Specifically, in a round bottom glass flask that contained the TBABB catalyst and was kept under argon the solvent (THF) and monomer were added. Then the MTS initiator was added at the end. For example, for the first polymer of the MEGMA series $25 \mathrm{~mL}$ of THF, $0.5 \mathrm{~mL}$ $(0.0025 \mathrm{~mol}, 0.43 \mathrm{~g})$ of MTS and $5.9 \mathrm{~mL}(0.040$ mol, $5.8 \mathrm{~g}$ ) of MEGMA were used. For the rest of the polymers in the same series the amount of MTS added was kept the same $(0.5 \mathrm{~mL})$ and what varied was the THF and the amount of MEGMA. The concentration of reagents in solution was kept constant at $25 \mathrm{wt} \%$ for all polymer syntheses as well as the amount of catalyst TBABB ( 10mg).

The polymerization was exothermic in all cases and the exotherm was monitored for each reaction that lasted less than 15 minutes. Then 
samples for gel permeation (GPC) and nuclear magnetic resonance (NMR) spectroscopy characterization were obtained. Finally, all polymers were precipitated in hexane and then dried in a vacuum oven over a week at room temperature.

Gel Permeation Chromatography (GPC). The gel permeation chromatography (GPC) was used to confirm the $\mathrm{MM}$ and the molar mass distribution (MMD) of the polymers synthesized in this project. The GPC machine used in this project was an Agilent, Security GPC system, with a Polymer Standard Service (PSS) SDV analytical linear $M$ column (SDA083005LIM). It was calibrated by poly(methyl methacrylate) (PMMA) standards with molar masses of 2000, 4000, 8000, 20000, 50000, and $100000 \mathrm{gmol}^{-1}$.

The samples were prepared by mixing $10 \mathrm{mg}$ of polymer and $1 \mathrm{ml}$ of GPC solvent. The solvent was either pure THF or THF with $5 \%$ vol of trimethylamine. The samples were filtered before passing through the device to protect the column from blockage.

Proton Nuclear Magnetic Resonance Spectroscopy ( ${ }^{1}$ H NMR) After precipitation, the polymer was determined by a $400 \mathrm{MHz}$ Advance Bruker NMR spectrometer instrument to confirm the synthesis. For each sample, around $0.01 \mathrm{~g}$ of polymer was dissolved in $650 \mu \mathrm{ml}$ of $\mathrm{d}$ chloroform.

Cloud point measurements. All the polymers were tested in $2 \mathrm{ml}$ of $1 \mathrm{w} / \mathrm{w} \%$ solutions. The solvent used were deionized water (DI water), PBS, ethanol, $80 \%$ water and $20 \%$ ethanol. The cloud points of the polymers were at first tested visually (between $20^{\circ} \mathrm{C}$ to $95^{\circ} \mathrm{C}$ ) and then by measuring the transmittance using a Cary 3500 Compact Peltier UV-Vis System (Agilent, UK).

Dynamic Light Scattering (DLS). The dynamic light scattering was used to determine the sizes of random coil or the micelles formed by the polymers in water solution. The $1 \mathrm{wt} \%$ water solutions of all the polymers were filtered and test under $25^{\circ} \mathrm{C}$. Since the cloud points of
TEGEMA polymers are around room temperature, the DLS of those polymers are conducted under $15^{\circ} \mathrm{C}$. The instrument used in this project was Zetasizer Nano ZSP (Malvern, UK).

Titration. Since the DMAEMA polymers are also $\mathrm{pH}$-sensitive, the titration was conducted to determine the effective $\mathrm{pK}_{\mathrm{a}} \mathrm{s}$ of these polymers. Firstly, around $5 \mathrm{ml}$ of $1 \mathrm{wt} \%$ solution was made. Then these solutions were titrated between $\mathrm{pH}$ 2 and $\mathrm{pH} 12$ using a standard $\mathrm{NaOH} 0.75 \mathrm{M}$ solution under continuous stirring. The $\mathrm{pH}$ was measured using a Fisherbrand Hydrus $400 \mathrm{pH}$ meter. The $\mathrm{pK}_{\mathrm{a}} \mathrm{s}$ were calculated as the $\mathrm{pH}$ at $50 \%$ ionization.

\section{RESULTS AND DISCUSSION}

In total 27 homopolymers with 7 different PEG methacrylate monomers were fabricated and 4 DMAEMA homopolymers were also synthesised for comparison. The target $\mathrm{MMs}$ of these polymers were aimed at $2560 \mathrm{~g} \mathrm{~mol}^{-1}, 5000 \mathrm{~g}$ $\mathrm{mol}^{-1}, 8000 \mathrm{~g} \mathrm{~mol}^{-1}$ and $12000 \mathrm{~g} \mathrm{~mol}^{-1}$. The PEG monomers studied were EEGMA, MEGMA, DEGMA, TEGMA, TEGEMA, PEGMA, and NEGMA. Only one polymer was not successfully synthesized, specifically TEGMA $A_{51}$ as it will be discussed below and thus is not reported in Table 1.

\section{Molar Mass and Molar Mass Distribution}

The MMs and the MMD (dispersity indices, $\boxminus$ ) given by GPC of all the homopolymers were presented in Table 1.

As shown in Table 1, the MMDs of these homopolymers were all lower than 1.21 similar to previous GTP polymerizations using PEG based methacrylates, indicating a successful polymerization. ${ }^{36,42,45,53,54,56-58}$ The MMDs of PEGMA and NEGMA polymers were slightly higher than others which agreed with previous studies. The first reason was the PEGMA and NEGMA are macromonomers with an average MM. The second reason was due to the high viscosity, instead of distillation, these monomers 
were filtered before polymerization, thus the remaining impurities in the monomer lead to wider MMDs. For most of the homopolymers, the resulted $\mathrm{M}_{\mathrm{n}} \mathrm{s}$ were slightly higher (around $15 \%)$ than the theoretical MMs. This was due to the deactivation caused by impurities in the flasks and/or the moisture introduced into the flask during the addition of the monomers, solvent and initiator.

Table 1 Molar masses (theoretical and as experimentally determined by GPC) and molar mass distribution of the PEG methacrylate based homopolymers

\begin{tabular}{|c|c|c|c|c|}
\hline \multirow[b]{2}{*}{ Sample No. } & \multirow[b]{2}{*}{ Chemical structure $^{a}$} & \multirow[b]{2}{*}{ Theoretical $\mathrm{MM}^{\mathrm{b}} \mathrm{g} \mathrm{mol}^{-1}$} & \multicolumn{2}{|c|}{ GPC results ${ }^{c}$} \\
\hline & & & $\begin{array}{c}M_{\mathrm{n}} \mathrm{g} \mathrm{mol}^{-1} \\
( \pm 250)\end{array}$ & $\begin{array}{c}M_{\mathrm{w}} / M_{\mathrm{n}} \\
( \pm 0.01)\end{array}$ \\
\hline 1 & $\mathrm{DEGMA}_{13}$ & 2560 & 3300 & 1.12 \\
\hline 2 & $\mathrm{DEGMA}_{27}$ & 5000 & 5600 & 1.14 \\
\hline 3 & $\mathrm{DEGMA}_{44}$ & 8300 & 11200 & 1.13 \\
\hline 4 & $\mathrm{DEGMA}_{63}$ & 12000 & 13900 & 1.12 \\
\hline 5 & TEGMA $_{10}$ & 2560 & 2700 & 1.17 \\
\hline 6 & TEGMA $_{21}$ & 5000 & 5500 & 1.17 \\
\hline 7 & TEGMA $_{35}$ & 8300 & 16400 & 1.08 \\
\hline 8 & $\mathrm{NEGMA}_{5}$ & 2560 & 4000 & 1.21 \\
\hline 9 & $\mathrm{NEGMA}_{10}$ & 5000 & 6500 & 1.14 \\
\hline 10 & $\mathrm{NEGMA}_{16}$ & 8300 & 9900 & 1.09 \\
\hline 11 & $\mathrm{NEGMA}_{24}$ & 12000 & 14000 & 1.14 \\
\hline 12 & $\mathrm{PEGMA}_{8}$ & 2560 & 3900 & 1.20 \\
\hline 13 & PEGMA $_{16}$ & 5000 & 5800 & 1.16 \\
\hline 14 & $\mathrm{PEGMA}_{27}$ & 8300 & 9300 & 1.18 \\
\hline 15 & $\mathrm{PEGMA}_{40}$ & 12000 & 14100 & 1.21 \\
\hline 16 & $\mathrm{MEGMA}_{16}$ & 2560 & 2500 & 1.14 \\
\hline 17 & $\mathrm{MEGMA}_{34}$ & 5000 & 5600 & 1.11 \\
\hline 18 & MEGMA $_{56}$ & 8300 & 11000 & 1.06 \\
\hline 19 & $\mathrm{MEGMA}_{83}$ & 12000 & 15800 & 1.08 \\
\hline 20 & EEGMA $_{15}$ & 2560 & 2600 & 1.11 \\
\hline 21 & EEGMA $_{31}$ & 5000 & 5000 & 1.12 \\
\hline 22 & EEGMA $_{51}$ & 8300 & 9500 & 1.08 \\
\hline 23 & $\mathrm{EEGMA}_{75}$ & 12000 & 14400 & 1.12 \\
\hline 24 & TEGEMA $_{10}$ & 2560 & 3000 & 1.15 \\
\hline 25 & TEGEMA $_{20}$ & 5000 & 6200 & 1.12 \\
\hline 26 & TEGEMA $_{33}$ & 8300 & 12700 & 1.11 \\
\hline 27 & TEGEMA $_{48}$ & 12000 & 15800 & 1.11 \\
\hline 28 & DMAEMA $_{16}$ & 2560 & 3400 & 1.12 \\
\hline 29 & DMAEMA $_{31}$ & 5000 & 7100 & 1.13 \\
\hline 30 & DMAEMA $_{52}$ & 8300 & 9400 & 1.10 \\
\hline 31 & DMAEMA $_{63}$ & 10000 & 13300 & 1.08 \\
\hline
\end{tabular}

a The abbreviations for the eight monomers: (ethylene glycol) methyl ether methacrylate (MEGMA), (ethylene glycol) ethyl ether methacrylate (EEGMA), di(ethylene glycol) methyl ether methacrylate (DEGMA), tri(ethylene glycol) methyl ether methacrylate (TEGMA), tri(ethylene glycol) ethyl ether methacrylate (TEGEMA), penta(ethylene glycol) methyl ether methacrylate (PEGMA), nona(ethylene glycol) methyl ether methacrylate (NEGMA) and 2-(dimethylamino) ethyl methacrylate (DMAEMA).

${ }^{\mathrm{b}}$ Theoretical $\mathrm{MM}=\mathrm{MM}_{\text {monomer }}{ }^{*} \mathrm{DP}+100 \mathrm{gmol}^{-1}$, where the $\mathrm{MM}_{\text {monomer }}$ was the molar mass of the monomer; the DP was the degree of polymerization of the corresponding homopolymer; the $100 \mathrm{gmol}^{-1}$ was the molar mass of the fragment of the MTS (the initiator) remaining on the polymer backbone.

${ }^{\mathrm{C}}$ As determined by GPC using poly(methyl methacrylate) PMMA standards. 
It should be noted that the synthesis of the TEGMA polymers was not straight forward. Even though the TEGMA was distilled due to its high MM higher temperature was used and took longer to distill than the other monomers. We believe that as often reported for EG based methacrylate monomers a small percentage of the hydroxy terminated equivalent was present that interfered with the polymerization and thus the higher MM polymer was not obtained after 3 trials. The monomer is no longer commercially available thus the polymerization cannot be repeated. The difficulty of obtaining polymers with TEGMA is also demonstrated by the fact that when we aimed for polymer 7, with a degree of polymerization equal to 35 a polymer with double the MM was obtained.

The GPC chromatograms of MEGMA homopolymers (for samples that were obtained directly from the polymerization flask) are shown in Fig.2. As shown in the figure, there is no shoulder or monomer peak on the curve indicating the $100 \%$ conversion of the monomer. The GPC chromatograms of the rest of the homopolymers can be found in Fig. S1.

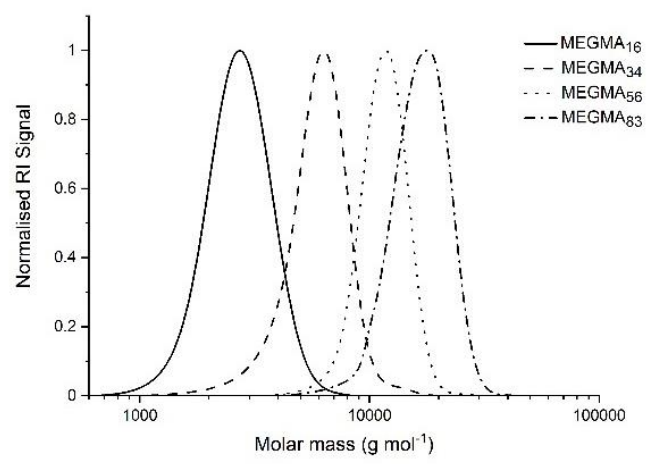

FIGURE 2 GPC chromatograms of MEGMA homopolymers. The theoretical MMs increased from 2560 to $12000 \mathrm{gmol}^{-1}$. The traces of $M \mathrm{MEMA}_{16}, \mathrm{MEGMA}_{34}, \mathrm{MEGMA}_{56}$, and MEGMA are shown in black solid, black dashed, black dotted and black dashed dotted lines, respectively.

The ${ }^{1} \mathrm{H}$ NMR spectrum of $\mathrm{MEGMA}_{16}$ in $\mathrm{d}$ chloroform is shown in Fig.3. The characteristic peaks at around $3.5 \mathrm{ppm}$ and $4 \mathrm{ppm}$ and were labelled as peak $d$ and peak $c$ in the spectrum. These peaks correspond to the protons in the methylene group $\left(-\mathrm{OCH}_{2}-\mathrm{CH}_{2}-\right)$ of MEGMA homopolymers. The peak e was due to the protons in the methoxy $\left(-\mathrm{OCH}_{3}\right)$ group. The peak $a$ and $b$ at around $1 \mathrm{ppm}$ correspond to the protons on the polymer backbone. Furthermore, one NMR spectra for one homopolymer from each of the 8 monomers is included in the supplementary information. Note that the degree of polymerization is not able to be determined by NMR when using GTP as only an MMA group is left on the polymer chain as it was previously mentioned and the 3 protons of the $\mathrm{CH}_{3}$ group overlap with the monomer groups.

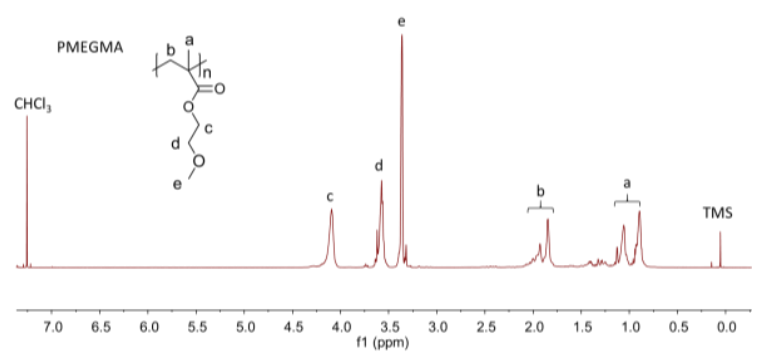

FIGURE $3{ }^{1} \mathrm{H}$ NMR spectrum of MEGMA ${ }_{16}$ in $\mathrm{d}$ chloroform.

\section{Aqueous Solution Properties}

\section{Cloud Point}

The cloud points of all the homopolymers obtained by visual tests in different solvent are listed in Table 2.

The cloud point was not tested for MEGMA and EEGMA homopolymers because they were not soluble in water, ethanol and $80 \% \mathrm{H}_{2} \mathrm{O}+20 \% \mathrm{C}_{2} \mathrm{H}_{6} \mathrm{O}$. This is due to the ethylene glycol groups in these polymers are not sufficient to achieve solubility. For NEGMA homopolymers, no cloud point was observed up to $95^{\circ} \mathrm{C}$. This is attributed to the fact that there are nine ethylene glycol groups in the monomer, the homopolymer is too hydrophilic, thus interrupting the "hydrophobic effect". 
Table 2 Cloud points of $1 \% \mathrm{w} / \mathrm{w}$ solutions in deionized water, PBS and $80 \% \mathrm{H}_{2} \mathrm{O}+20 \% \mathrm{C}_{2} \mathrm{H}_{6} \mathrm{O}$ and hydrodynamic diameters in $1 \% \mathrm{w} / \mathrm{w}$ solutions in water of the homopolymers.

\begin{tabular}{|c|c|c|c|c|c|c|}
\hline \multirow[b]{2}{*}{ Sample No. } & \multirow[b]{2}{*}{ Chemical structure } & \multicolumn{3}{|c|}{ Cloud Point $\left( \pm 1^{\circ} \mathrm{C}\right)$} & \multicolumn{2}{|c|}{ Hydrodynamic Diameter (nm) } \\
\hline & & Water & PBS & $80 \% \mathrm{H}_{2} \mathrm{O}+20 \% \mathrm{C}_{2} \mathrm{H}_{6} \mathrm{O}$ & $\mathbf{D}_{\text {theoretical }}^{\mathrm{d}}$ & $D_{\text {experimental }}( \pm 0.5)$ \\
\hline 1 & DEGMA $_{13}$ & 30 & 28 & 60 & 1.6 & 3.6 \\
\hline 2 & $\mathrm{DEGMA}_{27}$ & 29 & 26 & 59 & 2.0 & 4.2 \\
\hline 3 & $\mathrm{DEGMA}_{44}$ & 27 & 25 & 47 & 2.9 & 5.6 \\
\hline 4 & $\mathrm{DEGMA}_{63}$ & 27 & 24 & 46 & 3.2 & 6.1 \\
\hline 5 & TEGMA $_{10}$ & 63 & 56 & $-\mathrm{a}$ & 1.3 & 2.7 \\
\hline 6 & TEGMA $_{21}$ & 58 & 44 & 83 & 1.8 & 4.2 \\
\hline 7 & TEGMA $_{35}$ & 49 & 44 & 83 & 3.1 & 6.5 \\
\hline 8 & $\mathrm{NEGMA}_{5}$ & $-\mathrm{a}$ & $-{ }^{a}$ & $-a$ & 2.2 & 3.6 \\
\hline 9 & $\mathrm{NEGMA}_{10}$ & $-{ }^{a}$ & $-{ }^{a}$ & $-{ }^{a}$ & 2.4 & 4.2 \\
\hline 10 & $\mathrm{NEGMA}_{16}$ & $-\mathrm{a}$ & $-a$ & $-a$ & 2.6 & 4.9 \\
\hline 11 & $\mathrm{NEGMA}_{24}$ & $-{ }^{a}$ & $-^{a}$ & $-^{a}$ & 2.8 & 6.5 \\
\hline 12 & $\mathrm{PEGMA}_{8}$ & 76 & 71 & $-a^{a}$ & 2.0 & 3.3 \\
\hline 13 & PEGMA $_{16}$ & 75 & 71 & $-a$ & 2.2 & 4.2 \\
\hline 14 & $\mathrm{PEGMA}_{27}$ & 74 & 68 & $-a$ & 2.6 & 5.6 \\
\hline 15 & $\mathrm{PEGMA}_{40}$ & 71 & 68 & $-{ }^{a}$ & 2.9 & 6.5 \\
\hline 16 & $\mathrm{MEGMA}_{16}$ & $-b$ & $-b$ & $-b$ & 1.6 & $\mathrm{~N} / \mathrm{A}$ \\
\hline 17 & $\mathrm{MEGMA}_{34}$ & $-\mathrm{b}$ & $-b$ & $-b$ & 2.3 & $\mathrm{~N} / \mathrm{A}$ \\
\hline 18 & $\mathrm{MEGMA}_{56}$ & $-\mathrm{b}$ & $-\mathrm{b}$ & $-b$ & 3.3 & $\mathrm{~N} / \mathrm{A}$ \\
\hline 19 & MEGMA $_{83}$ & $-\mathrm{b}$ & $-b$ & $-b$ & 3.9 & $\mathrm{~N} / \mathrm{A}$ \\
\hline 20 & EEGMA $_{15}$ & $-b$ & $-b$ & $-b$ & 1.5 & $\mathrm{~N} / \mathrm{A}$ \\
\hline 21 & EEGMA $_{31}$ & $-\mathrm{b}$ & $-b$ & $-b$ & 2.1 & $\mathrm{~N} / \mathrm{A}$ \\
\hline 22 & $\mathrm{EEGMA}_{51}$ & $-b$ & $-b$ & $-b$ & 2.9 & $\mathrm{~N} / \mathrm{A}$ \\
\hline 23 & $\mathrm{EEGMA}_{75}$ & $-b$ & $-\mathrm{b}$ & $-b$ & 3.6 & $\mathrm{~N} / \mathrm{A}$ \\
\hline 24 & TEGEMA $_{10}$ & 26 & 22 & 33 & 1.3 & $3.1^{c}$ \\
\hline 25 & TEGEMA $_{20}$ & 24 & 22 & 32 & 1.9 & $4.2^{c}$ \\
\hline 26 & TEGEMA $_{33}$ & 24 & 22 & 29 & 2.7 & $6.5^{\mathrm{c}}$ \\
\hline 27 & TEGEMA $_{48}$ & 24 & 22 & 28 & 3.0 & $6.5^{\mathrm{c}}$ \\
\hline 28 & DMAEMA $_{16}$ & 46 & 46 & 84 & 1.4 & 3.6 \\
\hline 29 & DMAEMA $_{31}$ & 43 & 43 & 72 & 2.5 & 4.2 \\
\hline 30 & DMAEMA $_{52}$ & 43 & 36 & 64 & 2.9 & 4.2 \\
\hline 31 & DMAEMA $_{63}$ & 41 & 36 & 64 & 3.4 & 5.6 \\
\hline
\end{tabular}

aNo cloud point was observed even at $95^{\circ} \mathrm{C}$.

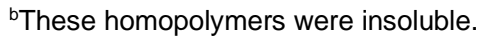

${ }^{\mathrm{C}}$ The DLS was conducted under $15^{\circ} \mathrm{C}$ because the cloud point of TEGEMA homopolymers was around room temperature.

$\mathrm{d}$ The theoretical hydrodynamic diameter was calculated by assuming that all the soluble polymer chains formed random coils in aqueous solution $\left(\left\langle\mathrm{dg}^{2}\right\rangle^{1 / 2}=2 *\left(2 * 2.20 * \mathrm{DP}_{\text {total }} / 3\right)^{1 / 2}{ }^{*} 0.154 \mathrm{~nm}\right)$; where $\mathrm{DP}_{\text {total }}$ is the total degree of polymerization as resulted from GPC result. For PEGMA and NEGMA polymers, the ethylene glycol side chain was long and should be considered when calculating the $\mathrm{DP}_{\text {total }}$.

Comparing the homopolymers with similar molar mass and different numbers of PEG groups on the side chain, the cloud points in DI water of the homopolymers were in this sequence: PEGMA $>$ TEGMA $>$ DEGMA $>$ TEGEMA, as shown in Fig.4. This agreed with the 
hydrophilicity of the monomers and was expected as summarized in the literature. ${ }^{5,24}$ When comparing DEGMA, TEGMA and PEGMA, the more the ethylene glycol groups in the monomer, the more hydrophilic the polymers are, therefore the higher the cloud point.

Concerning the terminal group on the side chain, i.e. methyl versus ethyl, it is observed that there is a strong effect on the thermoresponsive properties. More specifically, the cloud point of TEGEMA $_{10}$ is $38^{\circ} \mathrm{C}$ lower than TEGMA 10 . This is because the hydrophobicity of ethyl ether group is much higher than the methyl ether group, therefore the TEGEMA homopolymers are more hydrophobic than TEGMA homopolymers. Furthermore, it is worth noting that, the cloud point of TEGEMA 10 is $5^{\circ} \mathrm{C}$ lower than DEGMA even though it contains more ethylene glycol groups, which demonstrates that the terminal group on the side chain overcomes the effect of the number of EG groups on the side chain.

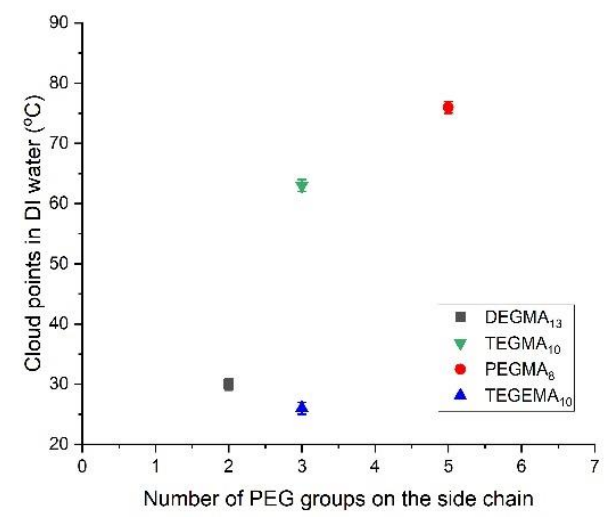

FIGURE 4 Effect of the number of PEG groups on the cloud points of the homopolymers with the same theoretical MM $\left(2560 \mathrm{gmol}^{-1}\right)$. The cloud points were tested in $1 \% \mathrm{w} / \mathrm{w}$ DI water solutions. The cloud points of the MEGMA homopolymer with the same target $\mathrm{MM}$ is not presented as the polymer is insoluble in water.

The cloud points of all the homopolymers were plotted against the experimental MMs as shown in Fig.5. The cloud points of these homopolymers decrease as the MMs increase, as expected, and observed before. ${ }^{18,40-45}$ The higher the MM, the higher the diameter of the polymers in solution as confirmed by the DLS in Table 2 thus the easier the aggregation and precipitation as the temperature increases. Therefore, it can be concluded that generally the higher the MM, the lower the cloud points. This effect seems to be more profound for more hydrophilic polymers as longer EG groups are presented and more thermoresponsive group on the polymer.

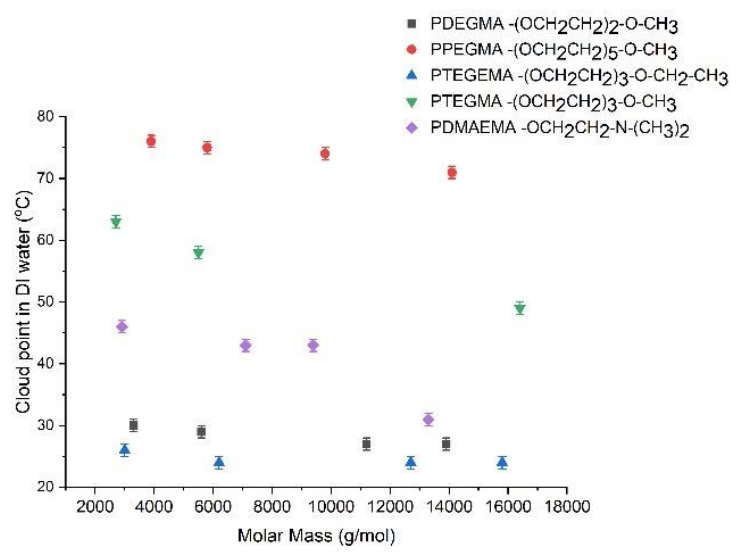

FIGURE 5 Effect of MM on the cloud points of the homopolymers. The cloud points were tested in $1 \% \mathrm{w} / \mathrm{w}$ DI water solutions.

When comparing the DMAEMA, MEGMA and EEGMA homopolymers it was found that both MEGMA and EEGMA polymers were not soluble while DMAEMA homopolymers exhibited cloud points between $35^{\circ} \mathrm{C}$ to $45^{\circ} \mathrm{C}$. The DMAEMA homopolymers cloud point decreased with increasing the $\mathrm{MM}$ as expected.

The cloud points of the homopolymers were also tested in other solvents such as PBS, ethanol, and a mixture of $80 \mathrm{wt} \%$ water and $20 \mathrm{wt} \%$ ethanol. There was no cloud point observed in the ethanol due to the good solubility of these homopolymers in the ethanol. However, for DEGMA, TEGMA, TEGEMA and DMAEMA homopolymers, cloud points were observed in the mixture of $80 \mathrm{wt} \%$ water and $20 \mathrm{wt} \%$ ethanol. The result of DEGMA homopolymers was plotted in Fig. 6 below. The same trend was observed for the other homopolymers and the diagram are given in the supplementary information. It was found that the homopolymer showed higher cloud point in DI water than in PBS (around $2-3^{\circ} \mathrm{C}$ higher), which was consisted with previous 
studies. ${ }^{27,} 32$ The cloud point increased as much as $30^{\circ} \mathrm{C}$ in the mixture of $80 \mathrm{wt} \%$ water and $20 w t \%$ ethanol when compared with DI water.

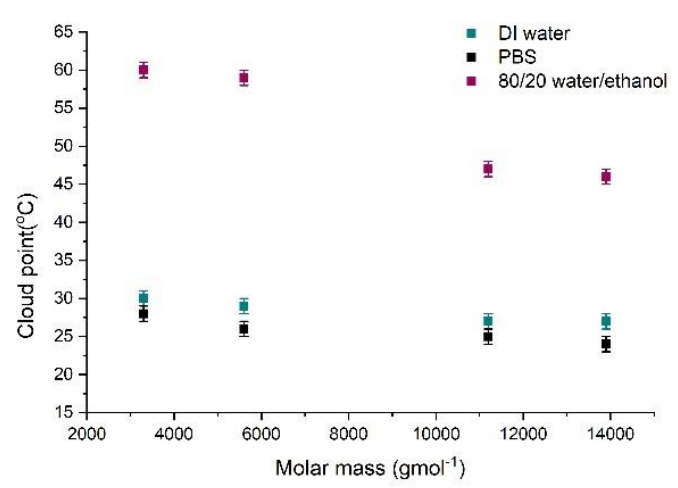

FIGURE. 6 Effect of different solvent on the cloud points of the DEGMA homopolymers.

\section{Hydrodynamic Diameter}

Table 2 includes the calculated theoretical hydrodynamic diameters and the experimental hydrodynamic diameters obtained from DLS of these homopolymers. The diameters at the maximum intensity on the DLS histogram were taken as the experimental hydrodynamic diameters. Since the TEGEMA polymers showed cloud points of 23 to $25^{\circ} \mathrm{C}$, the solutions were cloudy when firstly tested under room temperature. The results were around 2000$5500 \mathrm{~nm}$ which indicates that the polymer chains aggregated in the solution under room temperature. To avoid aggregation, the TEGEMA homopolymers were then tested under $15^{\circ} \mathrm{C}$ and the result was consistent with other homopolymers.

For the soluble homopolymers, the theoretical hydrodynamic diameters were calculated based on Equation. 1 by assuming that all the polymer chains formed random coils in aqueous solution. The DPexp was calculated by dividing the experimental $M M$ of the polymer by the $M M$ of the monomer. For DEGMA, TEGMA, TEGEMA and DMAEMA homopolymers, the DP total was considered equal to the $\mathrm{DP}_{\text {exp }}$.

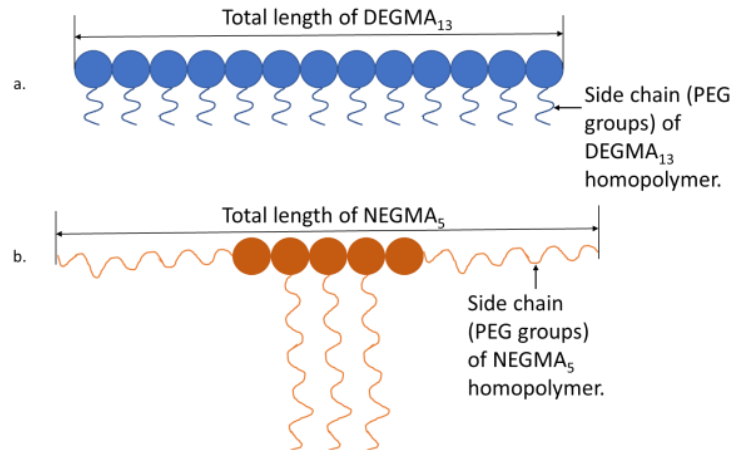

FIGURE 7 Schematic illustrations of the polymer chains of: a) $\mathrm{DEGMA}_{13}$ and b) $\mathrm{NEGMA}_{5}$ homopolymers.

However, for PEGMA and NEGMA, as shown in Fig.7, because the length of the PEG side chain is comparable with the backbone length, the length of side chains on each end of the polymer chain should be included in the total length of the polymer chain. The length of EG was considered as 1.5 times of the length of the methacrylate, thus the converted DP of the side chain was 1.5 times of the number of the EG group in the side chain. Therefore, the $\mathrm{DP}_{\text {total }}$ of NEGMA and PEGMA homopolymer was calculated differently using Equation.2. In Equation.2, $\mathrm{n}$ is the number of the EG group in the monomer.

$$
\begin{aligned}
& \left\langle d g^{2}\right\rangle^{1 / 2}=2 \times\left(2 \times 2.20 \times \frac{D P_{\text {total }}}{3}\right)^{1 / 2} \times 0.154 n m \\
& D P_{\text {total }}=D P_{\text {exp }}+2 \times n \times 1.5
\end{aligned}
$$

The experimental hydrodynamic diameters were close to the theoretical hydrodynamic diameters for all the polymers which indicates that the polymers existed in the solution as a random coil configuration. The hydrodynamic diameters increased as the MM increased. The influence of hydrophilicity of the homopolymers on the hydrodynamic diameters was minor. However, the experimental results were slightly higher than the theoretical ones. This was due to the assumptions made when calculating the theoretical hydrodynamic diameters. When calculating the theoretical hydrodynamic diameters, the polymer chains were assumed coiled and overlapped that this will not be the 
case when bulky side group like EG groups are presented. Furthermore, the experimentally determined diameters are hydrodynamic diameters i.e the solvent shell surrounding the polymer is taken into account, thus it is expected that they are larger than the theoretical calculation.

\section{Effective $p K_{a} S$}

The effective $\mathrm{p} K_{\mathrm{a}} \mathrm{s}$ of the DMAEMA homopolymers were determined and were in the range of 7.2 to 7.3 which agreed with previously reported $\mathrm{p} K_{\mathrm{a}}$ values of DMAEMA polymers. $^{36,42,44,53,54,56-58}$

\section{CONCLUSIONS}

In conclusion, a library of 27 homopolymers based on PEG methacrylate monomers and 4 homopolymers based on DMAEMA were successfully synthesized via GTP. The MMs were varied from $2560 \mathrm{~g} \mathrm{~mol}^{-1}, 5000 \mathrm{~g} \mathrm{~mol}^{-1}, 8200 \mathrm{~g}$ $\mathrm{mol}^{-1}$ to $12000 \mathrm{~g} \mathrm{~mol}^{-1}$ and the number of PEG groups in the side chain were varied from 1, 2, 3, 5,9 . The thermoresponsive properties of these monomers were investigated and compared. It was observed that the end group of the EG side group has a more dominant effect on the cloud point than the number of the EG or the MM of the polymer. This is an interesting result that can be used to tailor the LCST and gelling temperature of thermoresponsive copolymers.

\section{ACKNOWLEDGEMENTS}

\section{REFERENCES AND NOTES}

1. Constantinou, A. P.; Georgiou, T. K., Tuning the gelation of thermoresponsive gels. Eur. Polym. J. 2016, 78, 366-375.

2. Foster, J. C.; Akar, I.; Grocott, M. C.; Pearce, A. K.; Mathers, R. T.; O'Reilly, R. K., 100th Anniversary of Macromolecular Science Viewpoint: The Role of Hydrophobicity in Polymer Phenomena. ACS Macro Letters 2020.

3. Cook, M. T.; Haddow, P.; Kirton, S. B.; McAuley, W. J., Polymers Exhibiting Lower Critical Solution Temperatures as a Route to
Thermoreversible Gelators for Healthcare. $A d v$. Funct. Mater. 2020.

4. $\quad$ Zhang, Q.; Weber, C.; Schubert, U. S.; Hoogenboom, R., Thermoresponsive polymers with lower critical solution temperature: From fundamental aspects and measuring techniques to recommended turbidimetry conditions. Materials Horizons 2017, 4 (2), 109-116.

5. Vancoillie, G.; Frank, D.; Hoogenboom, R., Thermoresponsive poly(oligo ethylene glycol acrylates). Prog. Polym. Sci. 2014, 39 (6), 10741095.

6. Nele, V.; Wojciechowski, J. P.; Armstrong, J. P. K.; Stevens, M. M., Tailoring Gelation Mechanisms for Advanced Hydrogel Applications. Adv. Funct. Mater. 2020, 30 (42). 7. Zhang, L.; Chen, L.; Xiang, Y.; Liu, Z.; Mao, X.; Zhang, L.; Deng, L.; Zhang, Y.; Cheng, L.; Sun, X.; Cui, W., Multifunctional integrallymedicalized hydrogel system with internal synergy for efficient tissue regeneration. Chem. Eng. J. 2021, 406.

8. Hogan, K. J.; Mikos, A. G., Biodegradable thermoresponsive polymers: Applications in drug delivery and tissue engineering. Polymer 2020, 211.

9. Wu, Y.; Cai, Z.; Wu, S.; Xiong, W.; Ma, S., Protein purification by chemo-selective precipitation using thermoresponsive polymers. Biopolymers 2018, 109 (6), e23222.

10. Hsieh, F. Y.; Lin, H. H.; Hsu, S. H., 3D bioprinting of neural stem cell-laden thermoresponsive biodegradable polyurethane hydrogel and potential in central nervous system repair. Biomaterials 2015, 71, 48-57.

11. Iwami, K.; Noda, T.; Ishida, K.; Morishima, K.; Nakamura, M.; Umeda, N., Bio rapid prototyping by extruding/aspirating/refilling thermoreversible hydrogel. Biofabrication 2010, 2 (1), 014108.

12. Fentahun Darge, H.; Yibru Hanurry, E.; Simegniew Birhan, Y.; Worku Mekonnen, T.; Tizazu Andrgie, A.; Chou, H. Y.; Lai, J. Y.; Tsai, $\mathrm{H}$. C., Multifunctional drug-loaded micelles encapsulated in thermo-sensitive hydrogel for in vivo local cancer treatment: Synergistic effects of anti-vascular and immunochemotherapy. Chem. Eng. J. 2021, 406. 
13. Hinrichs, W. L. J.; SchuurmansNieuwenbroek, N. M. E.; van de Wetering, P.; Hennink, W. E., Thermosensitive polymers as carriers for DNA delivery. J. Controlled Release 1999, 60 (2), 249-259.

14. Lei, Z.; Wang, Q.; Wu, P., A multifunctional skin-like sensor based on a 3D printed thermo-responsive hydrogel. Materials Horizons 2017, 4 (4), 694-700.

15. Lutz, J.-F., Polymerization of oligo(ethylene glycol) (meth)acrylates: Toward new generations of smart biocompatible materials. Journal of Polymer Science Part A: Polymer Chemistry 2008, 46 (11), 3459-3470.

16. Lu, Y.; Yuan, J.; Polzer, F.; Drechsler, M.; Preussner, J., In situ growth of catalytic active Au-Pt bimetallic nanorods in thermoresponsive core-shell microgels. ACS Nano 2010, 4 (12), 7078-86.

17. Naya, M.; Kokado, K.; Landenberger, K. B.; Kanaoka, S.; Aoshima, S.; Sada, K., Supramolecularly Designed Thermoresponsive Polymers in Different Polymer Backbones. Macromol. Chem. Phys. 2020, 221 (5), 1900455. 18. Furyk, S.; Zhang, Y.; Ortiz-Acosta, D.; Cremer, P. S.; Bergbreiter, D. E., Effects of end group polarity and molecular weight on the lower critical solution temperature of poly(Nisopropylacrylamide). Journal of Polymer Science Part A: Polymer Chemistry 2006, 44 (4), 1492-1501.

19. Li, X.; Zhou, J.; Liu, Z.; Chen, J.; Lü, S.; Sun, H.; Li, J.; Lin, Q.; Yang, B.; Duan, C.; Xing, M.; Wang, C., A PNIPAAm-based thermosensitive hydrogel containing SWCNTs for stem cell transplantation in myocardial repair. Biomaterials 2014, 35 (22), 5679-5688.

20. Zhang, X. Z.; Wu, D. Q.; Chu, C. C., Synthesis, characterization and controlled drug release of thermosensitive IPN-PNIPAAm hydrogels. Biomaterials 2004, 25 (17), 3793805.

21. Mellati, A.; Valizadeh Kiamahalleh, M.; Dai, S.; Bi, J.; Jin, B.; Zhang, H., Influence of polymer molecular weight on the in vitro cytotoxicity of poly ( $\mathrm{N}$-isopropylacrylamide). Materials Science and Engineering: C 2016, 59, 509-513.
22. Wadajkar, A. S.; Koppolu, B.; Rahimi, M.; Nguyen, K. T., Cytotoxic evaluation of $\mathrm{N}$ isopropylacrylamide monomers and temperature-sensitive poly $(\mathrm{N}-$ isopropylacrylamide) nanoparticles. Journal of Nanoparticle Research 2009, 11 (6), 1375-1382. 23. Xue, C.; Yonet-Tanyeri, N.; Brouette, N.; Sferrazza, M.; Braun, P. V.; Leckband, D. E., Protein Adsorption on Poly(N-

isopropylacrylamide) Brushes: Dependence on Grafting Density and Chain Collapse. Langmuir 2011, 27 (14), 8810-8818.

24. Lutz, J. F., Thermo-switchable materials prepared using the OEGMA-platform. Adv.

Mater. 2011, 23 (19), 2237-2243.

25. Lutz, J.-F.; Andrieu, J.; Üzgün, S.;

Rudolph, C.; Agarwal, S., Biocompatible, Thermoresponsive, and Biodegradable: Simple Preparation of "All-in-One" Biorelevant Polymers. Macromolecules 2007, 40 (24), 85408543.

26. Lutz, J. F.; Hoth, A.; Schade, K., Design of oligo(ethylene glycol)-based thermoresponsive polymers: An optimization study. Des. Monomers Polym. 2009, 12 (4), 343353.

27. Badi, N.; Lutz, J. F., PEG-based thermogels: applicability in physiological media. J Control Release 2009, 140 (3), 224-9.

28. Lutz, J. F.; Weichenhan, K.; Akdemir, Ö.; Hoth, A., About the phase transitions in aqueous solutions of thermoresponsive copolymers and hydrogels based on 2-(2methoxyethoxy)ethyl methacrylate and oligo(ethylene glycol) methacrylate.

Macromolecules 2007, 40 (7), 2503-2508.

29. Lutz, J. F.; Akdemir, Ö.; Hoth, A., Point by point comparison of two thermosensitive polymers exhibiting a similar LCST: Is the age of poly(NIPAM) over? J. Am. Chem. Soc. 2006, 128 (40), 13046-13047.

30. Lutz, J. F.; Hoth, A., Preparation of ideal PEG analogues with a tunable thermosensitivity by controlled radical copolymerization of 2-(2methoxyethoxy)ethyl methacrylate and oligo(ethylene glycol) methacrylate. Macromolecules 2006, 39 (2), 893-896. 
31. Becer, C. R.; Hahn, S.; Fijten, M. W. M.; Thijs, H. M. L.; Hoogenboom, R.; Schubert, U. S., Libraries of methacrylic acid and oligo(ethylene glycol) methacrylate copolymers with LCST behavior. Journal of Polymer Science Part A: Polymer Chemistry 2008, 46 (21), 71387147.

32. Ramírez-Jiménez, A.; Montoya-Villegas, K. A.; Licea-Claverie, A.; Gónzalez-Ayón, M. A., Tunable thermo-responsive copolymers from DEGMA and OEGMA synthesized by RAFT polymerization and the effect of the concentration and saline phosphate buffer on its phase transition. Polymers 2019, 11 (10). 33. Akar, I.; Keogh, R.; Blackman, L. D.; Foster, J. C.; Mathers, R. T.; O'Reilly, R. K., Grafting Density Governs the Thermoresponsive Behavior of P(OEGMA-co-RMA) Statistical Copolymers. ACS Macro Letters 2020, 9 (8), 1149-1154.

34. Kudo, Y.; Mori, H.; Kotsuchibashi, Y., Preparation of an ethylene glycol-based block copolymer consisting of six different temperature-responsive blocks. Polym. J. (Tokyo, Jpn.) 2018, 50 (11), 1013-1020.

35. Roth, P. J.; Jochum, F. D.; Theato, P., UCST-type behavior of poly[oligo(ethylene glycol) methyl ether methacrylate] (POEGMA) in aliphatic alcohols: Solvent, co-solvent, molecular weight, and end group dependences. Soft Matter 2011, 7 (6), 2484-2492.

36. Constantinou, A. P.; Georgiou, T. K., Thermoresponsive gels based on $A B C$ triblock copolymers: Effect of the length of the PEG side group. Polym. Chem. 2016, 7 (11), 2045-2056.

37. Han, S.; Hagiwara, M.; Ishizone, T., Synthesis of Thermally Sensitive Water-Soluble Polymethacrylates by Living Anionic Polymerizations of Oligo(ethylene glycol) Methyl Ether Methacrylates. Macromolecules 2003, 36 (22), 8312-8319.

38. Vamvakaki, M.; Billingham, N. C.; Armes, S. P., Synthesis of water-soluble statistical copolymers and terpolymers containing pendent oligo(ethylene glycol derivatives). Polymer 1999, 40 (18), 5161-5171. 39. Pietsch, C.; Fijten, M. W. M.; Lambermont-Thijs, H. M. L.; Hoogenboom, R.;
Schubert, U. S., Unexpected reactivity for the raft copolymerization of oligo(ethylene glycol) methacrylates. J. Polym. Sci., Part A: Polym.

Chem. 2009, 47 (11), 2811-2820.

40. Boyer, C.; Whittaker, M. R.; Luzon, M.;

Davis, T. P., Design and Synthesis of Dual

Thermoresponsive and Antifouling Hybrid Polymer/Gold Nanoparticles. Macromolecules 2009, 42 (18), 6917-6926.

41. leong, N. S.; Hasan, M.; Phillips, D. J.; Saaka, Y.; O'Reilly, R. K.; Gibson, M. I., Polymers with molecular weight dependent LCSTs are essential for cooperative behaviour. Polym. Chem. 2012, 3 (3), 794-799.

42. Ward, M. A.; Georgiou, T. K., Thermoresponsive triblock copolymers based on methacrylate monomers: Effect of molecular weight and composition. Soft Matter 2012, 8 (9), 2737-2745.

43. Hoogenboom, R.; Thijs, H. M. L.; Jochems, M. J. H. C.; van Lankvelt, B. M.; Fijten, M. W. M.; Schubert, U. S., Tuning the LCST of poly(2-oxazoline)s by varying composition and molecular weight: alternatives to poly $(\mathrm{N}-$ isopropylacrylamide)? Chem. Commun. 2008, (44), 5758-5760.

44. Bütün, V.; Armes, S. P.; Billingham, N. C., Synthesis and aqueous solution properties of near-monodisperse tertiary amine methacrylate homopolymers and diblock copolymers.

Polymer 2001, 42 (14), 5993-6008.

45. Raduan, N. H.; Horozov, T. S.; Georgiou, T. K., "comb-like" non-ionic polymeric macrosurfactants. Soft Matter 2010, 6 (10), 2321-2329.

46. Giaouzi, D.; Pispas, S., PNIPAM-b-

PDMAEA double stimuli responsive copolymers: Effects of composition, end groups and chemical modification on solution selfassembly. Eur. Polym. J. 2020, 135. 47. Li, Z.; Hao, B.; Tang, Y.; Li, H.; Lee, T.C.; Feng, A.; Zhang, L.; Thang, S. H., Effect of end-groups on sulfobetaine homopolymers with the tunable upper critical solution temperature (UCST). Eur. Polym. J. 2020, 132, 109704.

48. Roth, P. J.; Jochum, F. D.; Forst, F. R.; Zentel, R.; Theato, P., Influence of end groups on the stimulus-responsive behavior of 
poly[oligo(ethylene glycol) methacrylate] in water. Macromolecules 2010, 43 (10), 46384645.

49. Jiang, X.; Zhao, B., End group effect on the thermo-sensitive properties of well-defined water-soluble polystyrenics with short pendant oligo(ethylene glycol) groups synthesized by nitroxide-mediated radical polymerization. Journal of Polymer Science Part A: Polymer Chemistry 2007, 45 (16), 3707-3721.

50. Webster, O. W., Group transfer polymerization: Mechanism and comparison with other methods for controlled polymerization of acrylic monomers. In Adv. Polym. Sci., 2004; Vol. 167, pp 1-34.

51. Webster, O. W.; Hertler, W. R.; Sogah, D. Y.; Farnham, W. B.; RajanBabu, T. V., GroupTransfer Polymerization. 1. A New Concept for Addition Polymerization with Organosilicon Initiators. J. Am. Chem. Soc. 1983, 105 (17), 5706-5708.

52. Dicker, I. B.; Cohen, G. M.; Farnham, W. B.; Hertler, W. R.; Laganis, E. D.; Sogah, D. Y., Oxyanions Catalyze Group-Transfer Polymerization To Give Living Polymers. Macromolecules 1990, 23 (18), 4034-4041.

53. Kyriacou, M. S.; Hadjiyannakou, S. C.; Vamvakaki, M.; Patrickios, C. S., Synthesis, characterization, and evaluation as emulsifiers of amphiphilic-ionizable aromatic methacrylate $\mathrm{ABC}$ triblock terpolymers. Macromolecules 2004, 37 (19), 7181-7187.
54. Hadjiyannakou, S. C.; Vamvakaki, M.; Patrickios, C. S., Synthesis, characterization and evaluation of amphiphilic diblock copolymer emulsifiers based on methoxy hexa(ethylene glycol) methacrylate and benzyl methacrylate. Polymer 2004, 45 (11), 3681-3692.

55. Bütün, V.; Vamvakaki, M.; Billingham, N. C.; Armes, S. P., Synthesis and aqueous solution properties of novel neutral/acidic block copolymers. Polymer 2000, 41 (9), 3173-3182. 56. Constantinou, A. P.; Lan, T.; Carroll, D. R.; Georgiou, T. K., Tricomponent thermoresponsive polymers based on an aminecontaining monomer with tuneable hydrophobicity: Effect of composition. Eur. Polym. J. 2020, 130.

57. Constantinou, A. P.; Sam-Soon, N. F.; Carroll, D. R.; Georgiou, T. K., Thermoresponsive Tetrablock Terpolymers: Effect of Architecture and Composition on Gelling Behavior. Macromolecules 2018, 51 (18), 7019-7031. 58. Constantinou, A. P.; Zhao, H.; McGilvery, C. M.; Porter, A. E.; Georgiou, T. K., A comprehensive systematic study on thermoresponsive gels: Beyond the common architectures of linear terpolymers. Polymers 2017, 9 (1). 
Qian Li, Anna P. Constantinou and Theoni K. Georgiou*

\section{A library of thermoresponsive PEG-based methacrylate homopolymers: How do the molar mass and number of ethylene glycol groups affect the cloud point?}

Ethylene glycol based methacrylate homopolymers have great potential in many biological applications. Here 27 homopolymers were synthesized and characterized in terms of their thermoresponsive properties. Interestingly the cloud point is not only affected by the number of ethylene glycol group and the molar mass but by also the terminal group on the ethylene glycol functional side group.

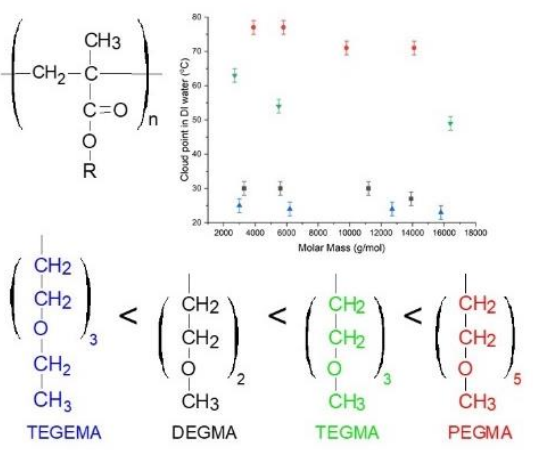

